
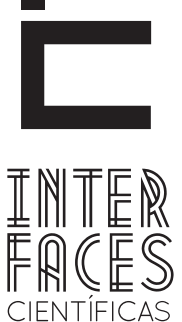

SAÚDE E AMBIENTE

ISSN IMPRESSO 2316-3313

E - ISSN 2316-3798

DOI - 10.17564/2316-3798.2017v5n3p57-66

\title{
QUALIDADE MICROBIOLÓGICA DE ÁGUAS DE COCO [COCUS NUCIFERA) COMERCIALIZADAS NO MUNICÍPIO DE ARACAJU, SE
}

\section{MICROBIOLOGICAL QUALTYY OF THE COCONUT WATER CCOCUS NUCIFERAJ COMMERCIALIZED ON THE STREETS IN THE CITY OF ARACAU, SE LA CALIDAD MICROBIOLÓGICA DEL AGUA DE COCO (COCUS NUCIFERA) QUE SE COMERCIALIZAN EN ARACAJU, SE}

Camila Pinheiro Costa Silva ${ }^{1}$

Thiago Lima da Silva ${ }^{3}$

Igor Adriano de Oliveira Reis ${ }^{5}$
Larissa Santos Oliveira ${ }^{2}$

José Augusto Andrade Filho ${ }^{4}$

\section{RESUMO}

A água de coco é uma bebida popularmente consumida na sua forma in natura em diversas regiões do Brasil. Quando envasada insere-se na linha dos produtos de conveniência, apresentando praticidade no manuseio e estocagem. A sua extração ocorre de forma artesanal ou mecânica, sendo preocupantes as condições higiênico-sanitárias nas quais são produzidos. Considerando o aumento do consumo deste alimento e os aspectos citados acima, o presente estudo teve como objetivo avaliar a qualidade microbiológica de águas de coco comercializadas no município de Aracaju, Sergi- pe. Os parâmetros microbiológicos contidos na resolução RDC no 12 de 2 de janeiro de 2001 (ANVISA) e, além destes, o número de coliformes totais foram determinados em 10 amostras de água de coco, adquiridas em distintos estabelecimentos comerciais. Verificou-se que $62,5 \%$ das amostras de água de coco extraídas e envasadas artesanalmente apresentaram coliformes acima do limite legal. Nas amostras em embalagens cartonadas não se detectou coliformes. Salmonella sp. foi detectada em apenas uma amostra. Conclui-se que a água de coco em embalagens Tetra Pak apresentava 
melhor qualidade microbiológica e a extraída e envasada artesanalmente apresentava a maior contaminação, sugerindo falha na aplicação de boas práticas para o envasamento e comercialização da água de coco.

\section{ABSTRACT}

Coconut water is commonly consumed as a juice in natura by population in different regions of Brazil. When potted inserts in the line of convenience products, with convenience in handling and storage. Its extraction takes place by hand or mechanical concern being the sanitary conditions in which they are produced. Contamination of drinking poses risks to public health may occur mainly due to factors such as inadequate packaging of raw materials, lack of hygiene prior coconut, unsatisfactory conditions of the facilities, equipment, containers used for the collection and the lack of knowledge of traders and handlers involved in the production chain. Considering the increasing consumption of this food and the

\section{RESUMEN}

El agua de coco es una bebida comúnmente consumida a natura en diversas regiones de Brasil. Cuando embotellada, es parte de la línea de productos de conveniencia, presentando comodidad en el manejo y almacenamiento. Su extracción ocurre a mano o mecánicamente, trayendo preocupación acerca de las condiciones higiénicas y sanitarias en las que se producen. Teniendo en cuenta el aumento del consumo de este alimento y los aspectos mencionados anteriormente, este estudio tuvo como objetivo evaluar la calidad microbiológica del mercado del agua de coco en el municipio de Aracaju, Sergipe. Parámetros microbiológicos contenidos en la Resolución RDC No. 12 del 2 de enero de 2001 (ANVISA) y, adicionalmente, se determinaron el número de coliformes totales en 10 muestras de agua de coco adquiridas a diferentes tiendas. Se en-

\section{PALAVRAS-CHAVE}

Água de coco, Qualidade microbiológica, Coliformes, Salmonella sp.

aspects mentioned above, the present study aimed to evaluate the microbiological quality of coconut water market in the city of Aracaju. We analyzed 10 samples of coconut water, acquired in different venues. It was found that the samples had some type of pathogenic microorganism, underscoring the need for active surveillance by regulatory agencies, advising marketers on the application of best practices for the bottling and marketing of coconut water safely.

\section{KEYWORDS}

Coconut water, Microbiological quality, Coliforms, Salmonellasp. contró que el $62,5 \%$ de las muestras de agua de coco extraídas a la mano, tenían coliformes por encima del límite legal. En las muestras de envases de cartón no se detectó coliformes. Salmonella sp. Fue detectado en una sola muestra. Se concluye que el agua de coco en envases de cartón tenían una mejor calidad microbiológica, ya la extraída y embotellada artesanalmente tenía el más alto de contaminación, lo que sugiere falta de aplicación de las buenas prácticas de embotellado y comercialización de agua de coco.

\section{PALABRAS CLAVES}

Agua de coco, Calidad microbiológica, Coliformes, Salmonellasp. 


\section{INTRODUÇ̄̃̃O}

O coqueiro (Cocus nucifera L.) é cultivado predominantemente no litoral da Região Nordeste, local de sua introdução pelos portugueses (CUENCA et al., 2002). A planta oferece as mais diversas possibilidades de utilização. Todas as suas partes, como raiz, caule, folha, inflorescência e fruto são empregados para fins artesanais, alimentícios, nutricionais, agroindustriais, medicinais e biotecnológicos, entre outros. Uma das suas principais utilidades atuais no Brasil, com grande perspectiva de uso internacional, é o aproveitamento da água de coco (ARAGÃO, 2002).

Aragão e outros autores (1998) definem que o fruto do coqueiro é formado por uma epiderme (casca) lisa ou epicarpo, de cor verde, amarelada, vermelha ou ainda marrom, de acordo com a variedade considerada, que envolve o mesocarpo espesso e fibroso, e, bem no interior, o endocarpo, que é uma camada muito dura. A semente, envolvida pelo endocarpo, é constituída por uma camada fina de cor marrom, o tegumento, que fica entre o endocarpo e o albúmen sólido. Este por sua vez, é uma camada carnosa, branca, muito oleosa, principalmente no fruto seco (entre 11 e 12 meses de idade). A semente forma uma cavidade, onde se encontra o albúmen líquido ou água de coco.

A água de coco corresponde a $25 \%$ do peso do fruto, onde a quantidade de água pode variar de $300 \mathrm{a}$ $600 \mathrm{~mL} /$ coco. Contém uma variedade de nutrientes, incluindo vitaminas, antioxidantes, aminoácidos, enzimas, fatores de crescimento e outros nutrientes. A água de coco é também uma boa fonte de minerais importantes, como magnésio, cálcio e potássio, que juntamente com os açúcares, conferem à mesma sabor agradável, tornando-a uma bebida isotônica natural (ARAGÃO et al., 1998).

É amplamente consumida na sua forma in natura, prática que envolve problemas relacionados ao transporte, armazenamento e perecibilidade do produto. Sendo assim, é justificável o desenvolvimento de técnicas de processamento que possibilitem o envase da água de coco, como inovação de embalagens e méto- dos de comercialização, viabilizando sua ampliação de comércio, possibilitando melhor conservação e menor exigência de espaço para o armazenamento e transporte. Além disso, há menores índices de contaminação por microrganismos externos, quando realizados todos os cuidados adequados (HOFFMAN et al., 2002).

Com o aumento da produção, sua conservação por meio de tratamentos térmicos é uma alternativa que amplia as possibilidades de comercialização pela venda do produto envasado. Essa conservação tem como finalidade aumentar o tempo de prateleira e assegurar as condições adequadas de higiene do produto, ocasionando alterações mínimas nas suas características nutricionais e sensoriais (ARAÚJO; FONTENELE; MERENDA, 2000).

Aragão (2002) afirma que a sua industrialização é de fundamental importância, pois permite o seu consumo em locais fora das regiões produtoras, visando diminuir o volume e o peso transportados e, consequentemente, reduzir os custos de transporte, bem como aumentar a sua vida de prateleira. Contudo, as indústrias de envasamento que vêm disponibilizando o produto vigorosamente no varejo, principalmente nos supermercados, restaurantes e lanchonetes enfrentam problemas de natureza microbiológica, pois, apesar de estéril, enquanto no interior do fruto, sua composição, rica em nutrientes de fácil assimilação, propicia o desenvolvimento microbiano, gerando problemas em sua conservação logo após abertura do fruto.

Aliadas às alterações de ordem microbiana, as alterações bioquímicas também contribuem para a diminuição da qualidade do produto, proporcionando modificações de cor e sabor decorrentes da ação de enzimas tais como as polifenoloxidases e peroxidases (SILVA; DANTAS; SILVA, 2009).

Dessa forma, a água de coco constitui também um veículo de contaminação microbiana. As principais causas podem ser por meio do acondicionamento inadequado da matéria-prima, da falta de higienização prévia do coco, das condições insatisfatórias das instalações, pela falta de conhecimento dos comerciantes e manipuladores envolvidos na cadeia de produção, e principalmente pela higienização inadequada 
de equipamentos e utensílios, podendo ser portadores de diversos microrganismos, que mesmo em pequenos níveis de contaminação, podem resultar em infecções alimentares (HOFFMANN et al., 2002).

A fim de avaliar a contaminação do alimento por bactérias, emprega-se a avaliação da presença de microrganismos indicadores que, quando presentes nos alimentos, podem fornecer características como contaminação, presença de patógenos, deterioração, além de indicar condições sanitárias inadequadas durante o processamento e armazenamento (FRANCO; LANDGRAF, 2003). De forma geral, os microrganismos indicadores são mais utilizados na avaliação da segurança e higiene alimentar do que na qualidade (FORSYTHE, 2005).

Como indicadores de contaminação fecal, os microrganismos mais utilizados são os coliformes, que inclui o grupo dos coliformes totais provenientes do ambiente e utilizado como indicadores da qualidade higiênica dos alimentos; e os coliformes fecais, onde sua pesquisa em alimentos é utilizada como indicador seguro das condições higiênicas do produto e ainda presença de enteropatógenos (FRANCO; LANDGRAF, 2003). Para a água de coco, a RDC 12/2001 possui padrões estabelecidos somente para coliformes termotolerantes e Salmonella sp.

O consumo de alimentos contaminados por microrganismos patogênicos como, por exemplo, a Salmonella sp., pode levar o indivíduo a um quadro infeccioso que varia de desconforto leve a reações severas, clinicamente manifestada por diarreia, náusea, vômitos, febre, cólicas, mal-estar e calafrios, podendo até mesmo causar a morte (BRASIL, 2010). Portanto, se faz necessária uma avaliação prévia da produção e distribuição dos alimentos comercializados, como também das pessoas que diretamente manipulam estes alimentos (SILVA; DANTAS; SILVA, 2009).

Tendo em vista os aspectos mencionados nesta pesquisa, a demanda crescente de água de coco e a precariedade higiênico-sanitária da cadeia produtiva e da comercialização, o presente trabalho objetivou avaliar alguns aspectos gerais de qualidade microbiológica, determinando a presença de indicadores de contaminação como coliformes totais e coliformes fecais e Salmonella sp., em amostras de água de coco nas formas I) envasadas e refrigeradas em garrafas mini-pet e II) industrializadas e envasadas em embalagens cartonadas, adquiridas em distintos estabelecimentos comerciais no município de Aracaju-SE.

\section{MÉTODOS}

Foram utilizados os meios de cultura: Água Peptonada, Caldo Lauril Sulfato Triptose, Verde Brilhante e Caldo EC, Caldo Selenito Cistina, Caldo Tetrationato, Ágar Entérico de Hektoen, Agar Bismuto Sulfito, Ágar Xilose Lisina Desoxicolato, Ágar Lisina Ferro, Ágar Tríplice Ferro (Synth, Brasil). Água Milli-QII (Millipore, EUA) foi usada para preparar todas as soluções aquosas. Seguindo as indicações do rótulo dos meios de cultura utilizados, prepararam-se as soluções.

Foram adquiridas 10 amostras de água de coco, sendo oito envasadas refrigeradas ( $A$ até $D$ ) e duas industrializadas (E), provenientes de 5 diferentes pontos comerciais do município de Aracaju-SE. As amostras foram mantidas em suas embalagens originais, lacradas e, sem qualquer possibilidade de contaminação externa, com aproximadamente $500 \mathrm{ml}$ cada. Em seguida, as amostras foram transportadas em caixas isotérmicas, contendo gelo ao Laboratório de Pesquisa de Alimentos do Instituto de Tecnologia e Pesquisa da Universidade Tiradentes, para análise imediata.

\subsection{TÉCNICAS MICROBIOLÓGICAS}

Todas as análises microbiológicas foram realizadas segundo o Compendium of Methods for the Microbiological Examination of Foods da American Public Health Association (APHA, 2001) e o Manual de Métodos de Análise Microbiológica de Alimentos (SILVA; JUNQUEIRA; SILVEIRA, 2007).

\subsubsection{CONTAGEM DE COLIFORMES TOTAIS E COLIFORMES TERMOTOLERANTES}


Para determinação de coliformes a $35^{\circ} \mathrm{C}$ e a $45^{\circ} \mathrm{C}$ utilizou-se a Técnica de Tubos Múltiplos, empregando-se nove tubos por amostra. Retirou-se, em condições assépticas, $25 \mathrm{ml}$ da amostra, colocando em um frasco, contendo $225 \mathrm{ml}$ de água peptonada 0,1\%, seguindo a posterior homogeneização, obtendo-se a diluição $10^{1}$. A partir desta diluição foram preparadas as diluições $10^{2}$ e $10^{3}$, pipetando $1 \mathrm{~mL}$ da diluição anterior e adicionando em $9 \mathrm{~mL}$ de água peptonada $0,1 \%$.

Após as diluições, foi realizado o teste inicial denominado presuntivo, que visa detectar a presença de microrganismos fermentadores de lactose, especialmente o grupo coliforme. Alíquotas de $1 \mathrm{~mL}$ de cada amostra, foram retiradas e inoculadas em 3 séries de 3 tubos, contendo $10 \mathrm{~mL}$ de caldo Lauril Sulfato Triptose e tubos de Durhan invertidos e devidamente esterilizados. Cada tubo foi homogeneizado e incubado a $35^{\circ} \mathrm{C}$ por 48 horas. Os tubos que apresentaram gás no tubo Durhan invertido, foram considerados como positivos. Transferiu-se uma alçada da cultura do tubo positivo para tubos de $10 \mathrm{ml}$ de Caldo Verde Brilhante com tubo de Durhan invertido e incubados em estufa à $35^{\circ} \mathrm{C}$ por 48 horas, para o teste confirmatório de coliformes totais.

Para o teste confirmatório de coliformes fecais, foi transferido uma alçada da cultura do tubo positivo para tubos de $10 \mathrm{ml}$ de Caldo EC com tubo de Durhan invertido e incubados em estufa a $44,5^{\circ} \mathrm{C}$ por 24 horas. Os resultados obtidos foram lidos e representados numericamente segundo a tabela de NMP (Número Mais Provável).

\subsubsection{PESQUISA DE SALMONELLASP.}

Para detecção de Salmonella sp., foi utlizada uma alíquota de $25 \mathrm{ml}$ diluída em $225 \mathrm{ml}$ de água peptonada e incubada a $35^{\circ} \mathrm{C}$ por $18-20 \mathrm{~h}$ (pré-enriquecimento). Posteriormente, volumes de $1 \mathrm{ml}$ foram transferidos para tubos contendo $10 \mathrm{ml}$ de Caldo Selenito Cistina (SC) e Caldo Tetrationato (TT) e incubados a $35^{\circ} \mathrm{C}$ por $24 \mathrm{~h}$ (enriquecimento). Foram realizados repiques em placas de Ágar Entérico de Hektoen (HE), Ágar Bis- muto Sulfito (BS) e Ágar Xilose Lisina Desoxicolato (XLD), e incubados a $35^{\circ} \mathrm{C}$ por $24 \mathrm{~h}$.

Colônias típicas foram isoladas em tubos inclinados de Ágar Lisina Ferro (LIA) e Ágar Tríplice Açúcar Ferro (TSI) e incubadas a $35^{\circ} \mathrm{C}$ por $24 \mathrm{~h}$. Os microrganismos isolados foram submetidos à identificação bioquímica: testes de urease, de indol, de fermentação da lactose e sacarose, de vermelho de metila e Voges-Proskauer, de citrato e de descarboxilação da lisina em caldo. Os resultados foram expressos como amostras com presença ou ausência de Salmonella sp.

\section{RESULTADOS E DISCUSSÕES}

Todos os resultados para as amostras de água de coco foram interpretados segundo a Resolução RDC $n^{\circ} 12$, de 2 de janeiro de 2001, do Ministério da Saúde que estabelece para água de coco um limite de tolerância de até $100 \mathrm{NMP} / \mathrm{mL}$ de coliformes termotolerantes e ausência de Salmonella sp. em $25 \mathrm{ml}$ da amostra. Já com relação aos coliformes totais, a atual Legislação Brasileira não estabelece limite em nenhum tipo de alimento, e sua classificação em satisfatório/insatisfatório foi baseada no padrão utilizado para coliformes fecais, permitido em até $100 \mathrm{NMP} / \mathrm{mL}$.

Os resultados das análises microbiológicas das amostras de água de coco extraídas e envasadas artesanalmente em garrafas mini-pet são apresentados na Tabela 1 . Das 8 amostras estudadas, verificou-se que $62,5 \%$ (5 amostras) apresentavam contaminações acima dos padrões estabelecidos pela legislação vigente por coliformes totais e fecais, sugerindo a ausência de boas práticas de higiene durante o processo produtivo, indicando que houve, no produto ou durante o processo, contato direto ou indireto com fezes humanas ou de animais de sangue quente, caracterizando uma deficiência na manipulação ou má higienização da matéria- prima. Também foi observado que em 12,5\% das amostras (1 amostra) foi encontrada a presença de Salmonella sp. 
Tabela 1 - Contagem de coliformes totais e fecais e detecção de Salmonella sp. em amostras extraídas e envasadas em garrafas mini-pet

\begin{tabular}{llll}
\hline Amostra & $\begin{array}{l}\text { Coliformes } \\
\text { totais } \\
(\mathrm{NMP} / \mathrm{mL})\end{array}$ & $\begin{array}{l}\text { Coliformes } \\
\text { fecais } \\
(\mathrm{NMP} / \mathrm{mL})\end{array}$ & $\begin{array}{l}\text { Salmonella } \\
\text { sp. (+/-) }\end{array}$ \\
\hline$A 2$ & $>2400$ & $>2400$ & $(-)$ \\
$B 1$ & $>2400$ & $>2400$ & $(+)$ \\
$C 1$ & $>2400$ & $>2400$ & $(-)$ \\
$C 2$ & $>2400$ & $>2400$ & $(-)$ \\
$A 1$ & 1100 & 1100 & $(-)$ \\
$B 2$ & 23 & 23 & $(-)$ \\
$D 1$ & 93 & 93 & $(-)$ \\
$D 2$ & 93 & 9 & $(-)$ \\
\hline
\end{tabular}

Fonte: Dados da pesquisa.

Os resultados apresentados pelas amostras “B2", "D1" e "D2" evidenciaram que houve o emprego das boas práticas durante o processo de extração e envase das amostras de água de coco, exibindo boa qualidade sanitária, diferente das amostras dos outros estabelecimentos comerciais, nas quais se subentende que a manipulação do fruto não foi de forma correta, caracterizando a presença de deficiências higiênico-sanitárias durante o processo. De acordo com a Associação Brasileira de Profissionais da Qualidade de Alimentos, todas as pessoas que tenham contato com qualquer etapa de processamento do alimento devem ser treinadas e conscientizadas a praticar as medidas de higiene e segurança, a fim de proteger os alimentos de contaminações químicas, físicas e microbiológicas (PROFIQUA, 1995 apud BADARÓ, 2007).

Resultados apresentados por Silva e outros autores (2009), em análise de 22 amostras de água de coco envasadas na cidade de Currais Novos-RN, demonstraram que $82 \%$ das amostras analisadas (dezoito amostras) e $22,7 \%$ (cinco amostras), apresentaram-se contaminadas por coliformes totais e fecais, respectivamente, sendo classificados como produto característico de condições higiênicas insatisfatórias e impróprio para o consumo, podendo causar enfermidades transmitidas por alimentos. Porém, na aná- lise para Salmonella sp. os resultados divergem dos dados apresentados pelo presente trabalho.

Fortuna e Fortuna (2008), ao estudarem as fontes de contaminação no processo produtivo de água de coco, verificaram por meio de questionários que entre os comerciantes havia diversos procedimentos de higiene inadequados, como manipulação do dinheiro, uso de panos sujos para limpar as mãos, roupas, unhas e mãos sujas; medidas que propiciam a contaminação por microrganismos patogênicos.

Com base no padrão estabelecido pela legislação brasileira para Salmonella sp. 12,5\% das amostras de água de coco analisadas não estavam aptas à comercialização e, consequentemente, ao consumo humano. Os valores encontrados assemelham-se aos apresentados por Hoffmann e colaboradores (2002) que ao realizarem o estudo microbiológico da água de coco in natura na cidade de São José do Rio Preto verificaram que em 16,7\% estavam presentes este microrganismo. Por ser potencialmente capaz de provocar infecção de origem alimentar, a presença desse microrganismo na água de coco classifica-a como produto impróprio para o consumo.

Os resultados encontrados diferem de trabalhos semeIhantes como o descrito por Serejo, Neves e Brito (2010), que avaliaram a qualidade microbiológica de 4 amostras de água de coco de um ponto de venda ambulante na cidade de São Luís, Maranhão, e observaram que as amostras apresentavam ausência de coliformes totais, mas no teste presuntivo detectou-se a presença de quaisquer outros microrganismos fermentadores de lactose, que não o grupo coliforme. Os autores atribuíram os resultados a má qualidade dos equipamentos, refletindo em risco de veiculação de algum patógeno pelo consumo do produto.

Nas amostras de água de coco industrializadas e embaladas em embalagens cartonadas (Tabela 2) obteve-se um menor nível de contaminação, atendendo aos padrões estabelecidos pela RDC 12 de 2 de janeiro de 2001, não expondo os consumidores aos riscos decorrentes de contaminação microbiana. Em relação à boa qualidade dessas amostras, pode-se afirmar que por serem processadas e envasadas por método asséptico em embalagem tetra pak, há no emprego do tratamento térmico a eliminação efetiva da microbiota patogênica, 
com o intuito de fornecer ao consumidor um produto de qualidade e segurança, com maior tempo de armazenamento, praticidade de transporte e armazenamento, favorecendo a comercialização da água de coco verde envasada (ROSA; ABREU, 2002).

Tabela 2 - Contagem de coliformes totais e fecais e detecção de Salmonella sp. em amostras industrializadas e embaladas em embalagens cartonadas

\begin{tabular}{llll}
\hline Amostra & $\begin{array}{l}\text { Coliformes } \\
\text { totais } \\
(\mathrm{NMP} / \mathrm{mL})\end{array}$ & $\begin{array}{l}\text { Coliformes } \\
\text { fecais } \\
(\mathrm{NMP} / \mathrm{mL})\end{array}$ & $\begin{array}{l}\text { Salmonella } \\
\mathrm{sp} \text { (+/-) }\end{array}$ \\
\hline$E 1$ & $<3$ & $<3$ & $(-)$ \\
$E 2$ & $<3$ & $<3$ & $(-)$ \\
\hline
\end{tabular}

Fonte: Dados da pesquisa.

Pinheiro e outros autores (2005) encontraram resultados semelhantes aos do presente trabalho ao realizar pesquisa de coliformes à $35^{\circ} \mathrm{C}$ e a $45^{\circ} \mathrm{C}$, e Salmonella sp. em três marcas de águas de coco comercializadas, produzidas pelo processo asséptico e envasadas em embalagens cartonadas coletadas nos supermercados de Fortaleza-CE. Os autores observaram que $100 \%$ das amostras de água de coco estavam dentro da legislação vigente, podendo ser consideradas seguras para o consumo humano. Os mesmos valores foram encontrados por Aoki e colaboradores (2012) ao investigarem a presença/ausência de bactérias do grupo coliformes em amostras de água de coco também em embalagens cartonadas adquiridas na cidade de Marília-SP. Segundo os autores, o processamento que as amostras passaram pelas diferentes indústrias conservou a qualidade, havendo boas práticas na colheita, lavagem, abertura do fruto, extração e envase, existindo ainda o emprego de tratamento asséptico e eliminação total dos microrganismos patogênicos.

\section{CONCLUSÃO}

Este estudo permitiu verificar uma maior incidência de microrganismos do grupo coliformes e Salmonella sp. nas amostras extraídas e envasa- das de maneira artesanal em garrafas mini-pet, indicando condições higiênicas-sanitárias inadequadas, decorrente de contaminação pós-processamento, limpeza e sanificações deficientes, e uma baixa contagem desses microrganismos nas amostras industrializadas submetidas a tratamento térmico. Com base nos padrões microbiológicos vigentes na legislação brasileira, apenas 2 pontos comerciais distribuíam água de coco classificadas como sendo próprias para o consumo humano.

Em vista dos resultados apresentados, sugere-se a necessidade de melhorias na capacitação quanto às boas práticas de manipulação e produção durante 0 processo de envasamento de água de coco, e ressalta-se a importância de uma fiscalização ativa por parte dos órgãos fiscalizadores.

\section{REFERÊNCIAS}

ARAGÃO, W.M. Fruto do coqueiro para consumo natural. In: ARAGÃO, W.M. (Ed.). Coco: pós-colheita. Brasília: Embrapa, 2002. p.19-25.

ARAGÃO, W.M. et al. Componentes dos frutos de cultivares de coqueiro-anão (Cocos nucifera). CPATC, n.64, p.1-3. 1998.

ARAÚJO, A.H.; FONTENELE, A.M.M.; MERENDA, A.P. Análise sensorial da água de coco in natura em comparação à pasteurizada. XVII Congresso Brasileiro de Ciência e Tecnologia de Alimentos, Anais ..., Fortaleza, 2000.

AOKI, E. et al. Qualidade microbiológica e análise sensorial de águas de coco in natura e industrializadas. Revista Analytica, São Paulo, ano X, n.57, p.52-59, 2012.

APHA (American Public Health Association). Compendium of methods for the microbiological examination of foods. Washington: APHA, 2001. 
BADARÓ, A.C.L. Boas práticas para serviços de alimentação: um estudo em restaurantes comerciais do município de Ipatinga, Minas Gerais. 2007. $172 f$. Dissertação (Mestrado) - Universidade Federal de Viçosa, Viçosa, 2007.

BRASIL. Ministério da Saúde. Secretaria de Vigilância em Saúde. Departamento de Vigilância Epidemiológica. Manual integrado da vigilância, prevenção e controle de doenças transmitidas por alimentos. Brasília: SEM, 2010.

CUENCA, M.A.G. et al. Mercado brasileiro do coco: situação atual e perspectivas. In: ARAGÃO, W.M. (Ed.). Coco: pós-colheita. Brasília: Embrapa, 2002. p.11-18.

\section{FORSYTHE, S.J. Microbiologia da segurança}

alimentar. Porto Alegre: Artmed, 2005.

FORTUNA, D.B.S.; FORTUNA, J.L. Avaliação da qualidade microbiológica e higiênico-sanitária da água-de-coco comercializada em carrinhos ambulantes nos logradouros do município de Teixeira de Freitas (BA). Rev. Baiana Saúde Públ., Salvador, v.32, n.2, p.203 217, 2008.

FRANCO, B.D.G.M.; LANDGRAF, M. Microbiologia dos alimentos. São Paulo: Atheneu, 2003.

HOFFMANN, F.L. et al. Qualidade microbiológica de amostras de água de coco vendidas por ambulantes na cidade de São José do Rio Preto-SP. Rev. Hig.

Alim., São Paulo, v.16, n.97, p.87-92, 2002.

PINHEIRO, A.M. et al. Caracterização química, físicaquímica, microbiológica e sensorial de diferentes marcas de água de coco obtidas pelo processo asséptico. Rev. Ciênc. Agron., v.3, n.2, p.209-214, 2005.

ROSA, M.F.; ABREU, F.A.P. Processos convencionais de conservação de água de coco. In: ARAGÃO, W.M. (Ed.). Coco: pós-colheita. Brasília: Embrapa, 2002. p.42-53.

SEREJO, M.T.; NEVES, M.A.; BRITO, N.M. Qualidade microbiológica de água de coco (Cocos nucifera) comercializada por ambulante na cidade de São Luís - MA. V Congresso Norte Nordeste de Pesquisa e Inovação, Anais ..., Maceió, 2010. Disponível em: <http://connepi.ifal.edu.br/ocs/index.php/connepi/ CONNEPI2010/paper/viewFile/1480/646>. Acesso em: 5 nov. 2013.

SILVA, J.L.A.; DANTAS, F.A.V.; SILVA, F.C. Qualidade microbiológica de águas de coco comercializadas no município de Currais Novos/RN. Holos, Natal, v.3, p.34-41, 2009.

SILVA, N.; JUNQUEIRA, V.C.A.; SILVEIRA, N.F.A. Manual de métodos de análise microbiológica de alimentos. São Paulo: Varela, 2007. 
1 Especialista em Nutrição Clínica: Metabolismo, Prática e Terapia Nutricional pela Universidade Estácio de Sá - UNESA. E-mail: camilanutri. cs@gmail.com

2 Instituto Federal Educação, Ciência e Tecnologia de Sergipe - IFS. Email: larissa8oliveira@gmail.com

3 Instituto Federal Educação, Ciência e Tecnologia de Sergipe - IFS. Email: thiago.silva@ifs.edu.br

4 Instituto Federal Educação, Ciência e Tecnologia de Sergipe - IFS. Email: augustoa@gmail.com

5 Instituto Federal Educação, Ciência e Tecnologia de Sergipe - IFS. Email: reisigoradriano@gmail.com 
